\title{
Morphology versus Vertical Phase Segregation in Solvent Annealed Small Molecule Bulk Heterojunction Organic Solar Cells
}

\author{
Alexander Kovalenko, ${ }^{1}$ Darina Stoyanova, ${ }^{2}$ Jan Pospisil, ${ }^{1}$ \\ Ivaylo Zhivkov, ${ }^{1,2}$ Ladislav Fekete, ${ }^{3}$ Daniela Karashanova, ${ }^{2}$ Irena Kratochvílová, ${ }^{3}$ \\ Martin Vala, ${ }^{1}$ and Martin Weiter ${ }^{1}$ \\ ${ }^{1}$ Materials Research Centre, Faculty of Chemistry, Brno University of Technology, Purkyňova 118, 61200 Brno, Czech Republic \\ ${ }^{2}$ Institute of Optical Materials and Technologies, Bulgarian Academy of Sciences, 109 Akademik G. Bonchev Street, P.O. Box 95, \\ 1113 Sofia, Bulgaria \\ ${ }^{3}$ Institute of Physics, Academy of Sciences of the Czech Republic v.v.i., Na Slovance 2, 18221 Prague 8, Czech Republic
}

Correspondence should be addressed to Alexander Kovalenko; kovalenko.alx@gmail.com

Received 16 September 2015; Accepted 11 October 2015

Academic Editor: Cheuk-Lam Ho

Copyright (C) 2015 Alexander Kovalenko et al. This is an open access article distributed under the Creative Commons Attribution License, which permits unrestricted use, distribution, and reproduction in any medium, provided the original work is properly cited.

The deep study of solvent annealed small molecules bulk heterojunction organic solar cells based on $\mathrm{DPP}(\mathrm{TBFu})_{2}: \mathrm{PC}{ }_{60} \mathrm{BM}$ blend is carried out. To reveal the reason of the solvent annealing advantage over the thermal one, capacitance-voltage measurements were applied. It was found that controlling the vertical phase segregation in the solar cells a high fullerene population in the vicinity of the cathode could be achieved. This results in increase of the shunt resistance of the cell, thus improving the light harvesting efficiency.

\section{Introduction}

Small molecular bulk heterojunction organic solar cells (BHJ OSCs) [1-6] exceed 10\% power-conversion efficiency (PCE) in multiple [7] and over 9\% in single [8] junction arrangement which is a prospective alternative for polymer solar cells. They do not suffer from batch-to-batch differences and demonstrate repeatable synthesis accuracy, which is a significant advantage in the mass production. In its turn, solution processed BHJ OSCs are nowadays very appealing due to the extremely simple processing $[9,10]$, flexibility [11], color tenability, and unbeatable low weight [11].

One of the prospective structural classes of donors in $\mathrm{BHJ}$ SCs diketopyrrolopyrrole (DPP) derivatives shows excellent photovoltaic performance both as a part of polymers [12-15] and as dimers [16-18], because of a low band gap, enabling them to absorb a large portion of the solar spectrum, as well as an ability to be further functionalized [19-23] to match the parameters required for the photovoltaic applications. Among the DPP monomers, DPP(TBFu $)_{2}$ ethyl-hexyl alkylated derivative showing high power-conversion efficiency (PCE) up to $4.4-4.8 \%$ with $\mathrm{PC}_{70} \mathrm{BM}[24,25]$ and $4.0 \%$ with $\mathrm{PC}_{60} \mathrm{BM}$ [26] represents the most successful design. Applying solvent annealing for the $\mathrm{DPP}(\mathrm{TBFu})_{2}: \mathrm{PC}_{70} \mathrm{BM}$ blend 5\% of PCE can be exceeded [27], which is, up to now, the highest reported PCE among the monomeric DPP derivatives. Consequently, $\mathrm{DPP}(\mathrm{TBFu})_{2}$ is often used as a benchmark compound in the current research dealing with new small molecular donors [28-30], acceptors [31], or tandem cells [32].

In the present paper, we investigate the influence of the solvent treatment on the optical and electrical properties of $\mathrm{DPP}(\mathrm{TBFu})_{2}: \mathrm{PC}_{60} \mathrm{BM}$ based solar cells, as far as it has been shown [27] that the solvent annealed devices can exceed the thermally annealed ones in terms of efficiency. Here, we present extended study of the abovementioned 
phenomenon including the precise electrical measurements of the devices [33-38], which allows getting deeper insight into the processes ongoing in the devices, mainly into the interface of the solvent treated top contact.

\section{Experimental Section}

2.1. Materials. $\mathrm{PC}_{60} \mathrm{BM}$ (Solenne, 99\%), chloroform (Aldrich, 99.9\%), $\mathrm{MoO}_{3}$ (Aldrich, 99.98\%), and Al (Aldrich, 99.99\%) were used as received without further purification. Prior to dissolving, materials for the active layer were kept in vacuum at $60^{\circ} \mathrm{C}$ overnight and then transferred to the nitrogen atmosphere. The solutions for the active layer films were prepared from a DPP : $\mathrm{PC}_{60} \mathrm{BM}$ blend (1.5:1 by weight) in chloroform with a total concentration of $20 \mathrm{mg} / \mathrm{mL}$ following the sonication for 5 minutes until complete DPP dissolution. All manipulations were carried out in a glovebox under nitrogen atmosphere unless otherwise stated.

2.2. Device Fabrication. For the device fabrication glass substrates with patterned ITO (Ossila) were preliminary cleaned in ultrasonic bath firstly in the $5 \% \mathrm{NaOH}$ solution, then rinsed in water, and consequently washed twice in deionized water. Finally, ultrasonic treatment in isopropanol bath was applied for 10 minutes at room temperature. Then the substrates were covered with PEDOT : PSS by spin coating at $5500 \mathrm{rpm}$ for 60 seconds followed by consequent annealing for 10 minutes at $150^{\circ} \mathrm{C}$ in the air and 10 minutes at $150^{\circ} \mathrm{C}$ in nitrogen atmosphere to remove residual moisture. $\mathrm{DPP}(\mathrm{TBFu})_{2}: \mathrm{PC}_{60} \mathrm{BM}$ heterojunction layer was deposited by dynamic spin coating dropping $25 \mu \mathrm{L}$ of the prepared solution on substrates prerotated at $2500 \mathrm{rpm}$ keeping the rotation for 40 seconds.

2.3. Solvent Annealing Treatment (SVT). Solvent annealing was applied in nitrogen atmosphere at temperature of $25^{\circ} \mathrm{C}$. $2 \mathrm{~mL}$ of each solvent was injected into a $30 \mathrm{~mm}$ glass Petri dish and then it was closed for $20 \mathrm{~min}$ to achieve the saturation of the volume with solvent vapors. Then as-cast film was attached on the back side of a second Petri dish lid, which was quickly swapped with the lid covering the solvent-containing Petri dish. The film was about $1 \mathrm{~cm}$ above the solvent level during the SVT. After certain duration, the film was removed from the treatment chamber.

Finally Al cathode layers were deposited in the same vacuum cycle over all untreated and SVT samples.

2.4. Characterization Techniques. Thickness of all the layers measured by the Dektak XT profilometer was in a range of $100 \pm 10 \mathrm{~nm}$. PCE measurement was performed under standard condition by AAA certified Abet Sun solar simulator with an air mass (AM) $1.5 \mathrm{G}$ filter. The simulated light intensity was adjusted to $1000 \mathrm{~W} \mathrm{~m}^{-2}$ by using a NRELcalibrated Si solar cell. The following results are based on 24 electrodes statistics (4 devices of 6 electrodes for each measurement) for each type of device.

Capacitance-voltage measurements were performed on Solartron SI 1260 Impedance/Gain-Phase Analyzer

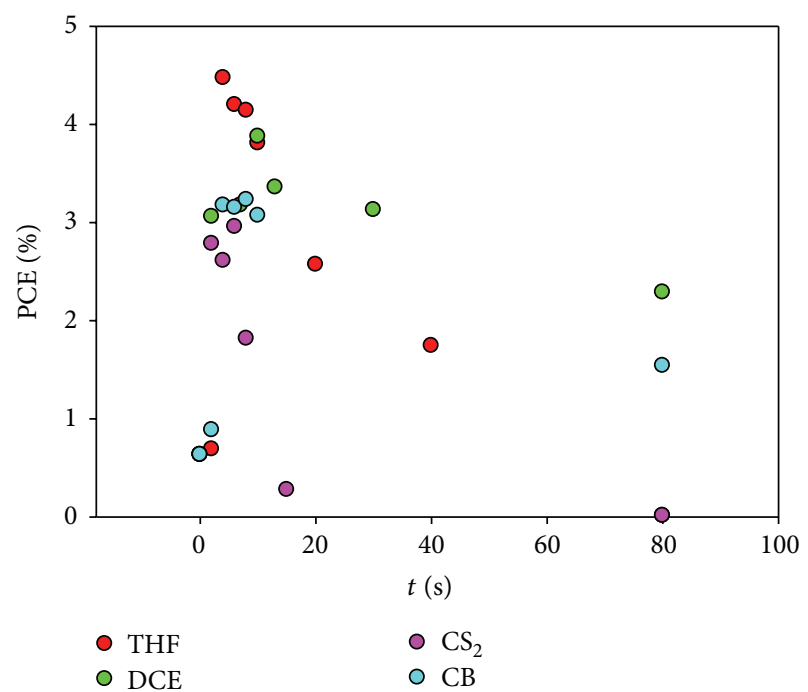

Figure 1: Power-conversion efficiencies of the variously solvent treated $\mathrm{BHJ}$ organic solar cells.

with Solartron Dielectric Interface 1296 device in ambient conditions with no light illumination applied. To study the surfaces of the as-cast and annealed thin layers AFM and TEM techniques were used.

The AFM pictures were taken by Bruker Dimension Icon ambient microscope. Kelvin probe measurement was performed using PFQNE-Al tips (spring constant $0.4 \mathrm{~N} / \mathrm{m}$, frequency $200 \mathrm{kHz}$, and nominal tip radius $5 \mathrm{~nm}$ ). The Kelvin potential was obtained from distance $20-30 \mathrm{~nm}$ above the grounded samples. Pictures have resolution of $512 \times 512$.

TEM study was performed by High Resolution Scanning Transmission electron microscope HR STEM JEOL JEM 2100, acceleration voltage was $80-200 \mathrm{kV}$, maximum resolution was $0.23 \mathrm{~nm}$ between two points, and maximum magnification was $1500000 x$ in conventional and $2000000 x$ in scanning mode, with 5 basic regimes, bright field and dark field microscopy, diffraction from selected and nanosized area, and diffraction in focused beam, equipped with CCD camera GATAN Orius 832 SC1000 and GATAN Microscopy Suit Software.

\section{Results and Discussion}

A set of regular architecture (ITO/PEDOT:PSS/ $\left.\mathrm{DPP}(\mathrm{TBFu})_{2}: \mathrm{PC}_{60} \mathrm{BM} / \mathrm{Al}\right)$ devices were prepared using various conditions of SVT. As a solvent THF, DCE, $\mathrm{CS}_{2}$, and $\mathrm{CB}$ were chosen. For each solvent several treatment periods were applied to get the clear picture of the solvent influence on the active layer. All the samples were treated until notable degradation of device performance was observed.

As it is shown in Figure 1 using solvent annealing results in high PCE, the best results were obtained using THF solvent. Applying THF for a solvent annealing for 4 seconds, we reached an average PCE value of $\sim 4.5 \%$ which is notably 
TABLE 1: Main photovoltaic parameters of as-cast, solvent annealed (THF for $4 \mathrm{~s}$ ), and thermally annealed (110 ${ }^{\circ} \mathrm{C}$ for $10 \mathrm{~min}$ ) devices.

\begin{tabular}{lcccccc}
\hline Device & PCE $[\%]$ & $V_{\mathrm{oc}}[\mathrm{mV}]$ & $J_{\mathrm{sc}}\left[\mathrm{mA} / \mathrm{cm}^{2}\right]$ & $\mathrm{FF}[\%]$ & $R_{\mathrm{sh}}\left[\mathrm{Ohm} \cdot \mathrm{cm}^{2}\right]$ & $R_{s}\left[\mathrm{mOhm} \cdot \mathrm{cm}^{2}\right]$ \\
\hline As-cast & 0,65 & 963,47 & 2,43 & 27 & 9263 & 189252 \\
Solvent annealed & 4,51 & 848,72 & 9,17 & 59 & 21318 & 7639 \\
ThA & 3,40 & 830,71 & 7,61 & 49 & 6469 & 15426 \\
\hline
\end{tabular}

higher than the thermally annealed reference devices prepared in the same conditions (PCE of $\sim 3.4 \%$ was measured). Generally, the best results were obtained with THF and DCE solvents applied for 4 and 10 seconds, respectively. Hereafter, samples treated in THF for $4 \mathrm{~s}$ will be considered SVT ones. All the solar cells except the overannealed degraded devices have shown good reproducibility in the range of $\pm 0.2 \%$ PCE.

Main photovoltaic parameters of as-cast, solvent annealed (THF for $4 \mathrm{~s}$ ), and thermally annealed $\left(110^{\circ} \mathrm{C}\right.$ for $10 \mathrm{~min}$ ) devices are stated in Table 1.

As it can be seen from Table 1 solvent annealing (THF $4 \mathrm{~s})$ results in PCE augmentation mostly by the improving the fill factor (FF), namely, by notable increase in the shunt resistance $\left(R_{\mathrm{sh}}\right)$ (see Figure 3$) . R_{\mathrm{sh}}$ in its turn can be influenced by the vertical phase segregation; high fullerene (electron transport material) cathode population reduces cell shunting as far as electrons can be easily transferred from the fullerene to cathode. Indeed, it is known that the thermal or solvent annealing can result in the vertical phase segregation in the particular components of $\mathrm{BHJ}[37,39]$. To get deeper insight into the processes ongoing in the devices we performed capacitance-voltage measurements in order to reveal the changes of fullerene population on the top (cathode) contact. $C-V$ measurement has proven to be a precise way to control a vertical segregation in working devices $[37,39]$. In its turn, correct contacts population is a significant parameter to reduce shunting in the solar cell [3741], thus improving OSCs performance.

$\mathrm{DPP}(\mathrm{TBFu})_{2}$ material needs to be either thermally annealed [24, 25] or solvent [27] annealed which results in reorganization of the solid state ordering of the material. However, it cannot explain the advantage of the SVT over the thermally annealed samples; optical spectra of the SVT samples are identical to thermally treated ones (see Figure 2). Solvent treatment results in significant changes in crystallinity of $\mathrm{DPP}(\mathrm{TBFu})_{2}$ analogously to the thermal treatment, which is derived from aggregation/interchain interactions, and increase in the crystallinity of material, which enhances the probability of optically active $\pi-\pi^{*}$ electronic transition, thus improving the PCE [24]. To explain this phenomenon we performed electrical measurements such as Mott-Schottky analysis to find a possible explanation of the abovementioned occurrence.

From the $C-V$ measurements of the THF solvent annealed samples it is clearly seen that initial changes in the vertical phase distribution are observed in reducing the flat-band potential and increasing the carrier density of the layers which is associated with the reorganization of the crystal structure and emersion of the fullerene on top of the layer. Longer solvent annealing for 20 and 40 seconds caused

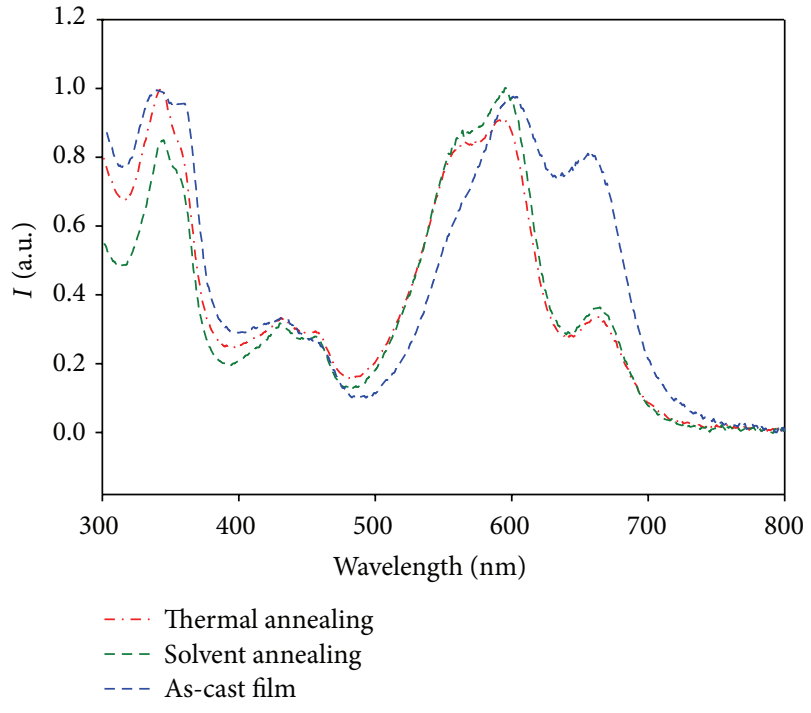

FIGURE 2: Absorption spectra of as-cast, thermal, and solvent annealed $\mathrm{DPP}(\mathrm{TBFu})_{2}: \mathrm{PC}_{60} \mathrm{BM}$ blend thin layers.

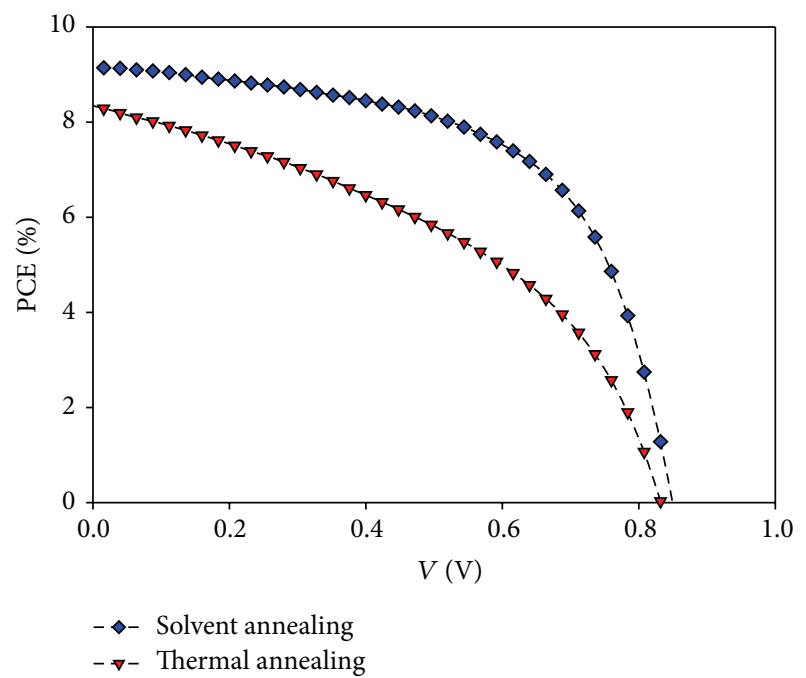

FIGURE 3: $J$ - $V$ curve of the thermally versus solvent annealed devices.

further decrease of the flat-band potential and it is nearly equal to the one of the reference pure PCBM device; thus, we can state that the top cathode contact is mostly covered with PCBM, which results in reducing recombination processes in the solar cell and improves its performance (Figure 4). Further solvent annealing for 60 and 80 seconds (PCE 


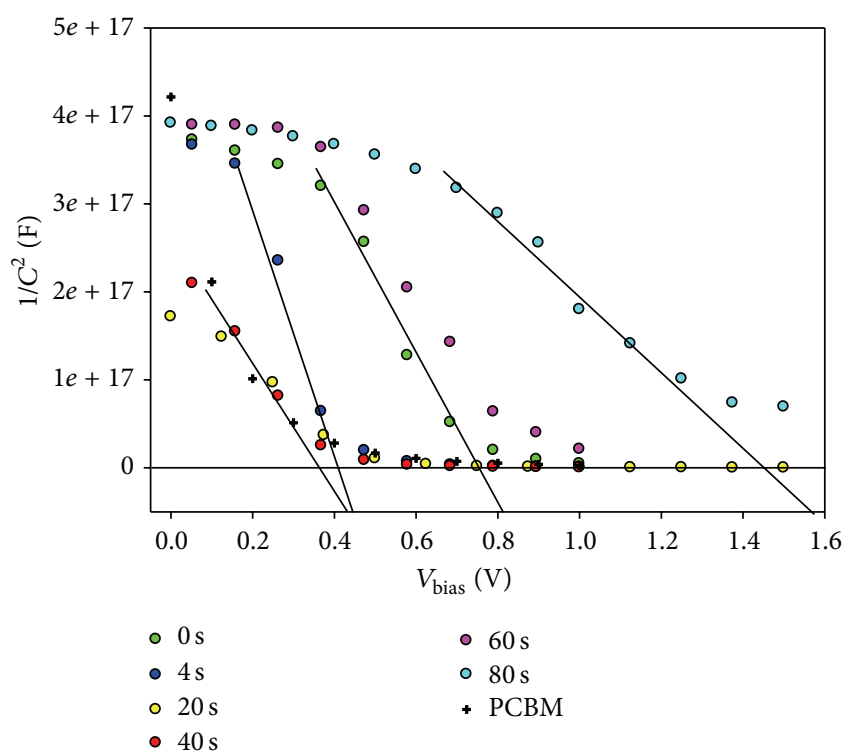

(a)

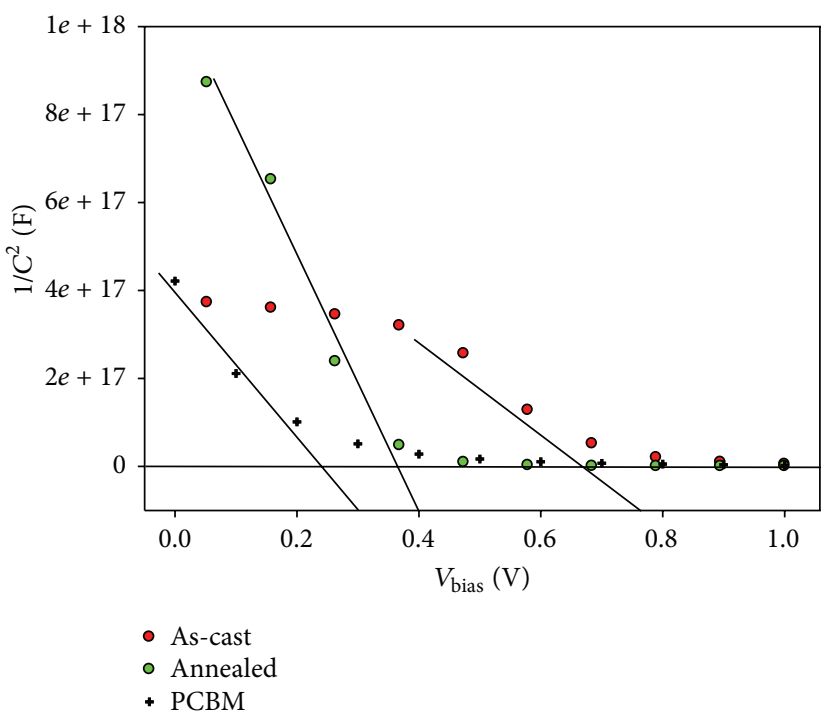

(b)

FIgURE 4: $C-V$ measurements of the THF solvent (a) and thermally (b) treated devices in comparison with pure $\mathrm{PC}_{60} \mathrm{BM}$ layer.

dramatically dropped) has shown the opposite behavior; flat-band potential is increasing; however, carrier density is decreased. We associate this fact with degradation of the material.

To study the phase segregation between donor and acceptor in the as-cast and solvent annealed layers, detailed study of the samples' surface was performed using the AFM. As it can be seen from Figure 5(a), well organized crystallites can be observed at the surface of the as-cast layer which indicates high DPP ratio on the surface. However, after 4 seconds of SVT in THF, one can observe a distinct structure on the surface (Figure 5(b)) which is assumed to be a full fullerene population of the sample's surface and how it was proved by the electrical measurement. Degraded sample (80 seconds of THF SVT) in Figure 5(c) had a surface with perceptible crystallites and with several relatively large aggregations. It can be seen from Figure 4(a) that degraded sample possessed high population of the donor material on the surface. We associate this phenomenon with the acceptor degradation after SVT treatment.

To get the deeper insight we performed AFM Kelvin probe measurements on the abovementioned samples. Kelvin probe is known to be efficient method repeatedly used to observe donor-acceptor domains in the BH OSCs [42-44]. The Kelvin probe force microscope measures the height variations on the sample surface and, simultaneously, employs the electrostatic forces between sample and tip which as a result yield the contact potential (CP) $[45,46]$. All the samples were measured in the air at ambient conditions with no light illumination applied. However, for the precise quantitative study of the materials' work function samples have to be measured in ultrahigh vacuum, and we do not consider the absolute values of the materials under study. Here, Kelvin probe images demonstrate staunchly relative overview: total work function of the images is nonnormalized; thus, by its difference one can observe separate domains of the donor and acceptor materials.

From Figure 6, it can be seen that the best performing sample (Figure 6(b)) as compared with as-cast sample (Figure 6(a)) has different crystalline structure and, importantly, the difference in surface potential in case of SVT sample is much lower, which is associated with predominant onephase population of top contact: fullerene in the present case. Also, abovementioned large aggregations possess notably higher work function in comparison to the rest of the sample's surface; thus, it can be assumed that the soluble acceptor $\mathrm{PC}_{60} \mathrm{BM}$ creates large crystallites on the surface and at the same time bares the donor material at the cathode, which crucially deteriorates the performance of the solar cells.

The microstructure of the films studied by TEM is presented in Figure 7. As it could be seen, the initial, as-cast film (Figure 7(a)) was grown continuously with plume-like morphology of the grains. Because of the existing anisotropy, the size of the features was estimated to be about 150-200 nm for the shorter side and few times higher along the plumes. Two types of electronic contrast existed on the image. The darker areas were probably due to the thick and denser grains, whose presence on the surface was confirmed by AFM image in Figure 6(a). The white areas or areas with less electronic contrast presented a rather not organized matter distributed around the grains. It is not possible by means of TEM to associate the areas with the different contrast to the different components of the film: DPP and PCBM. SAED patterns 


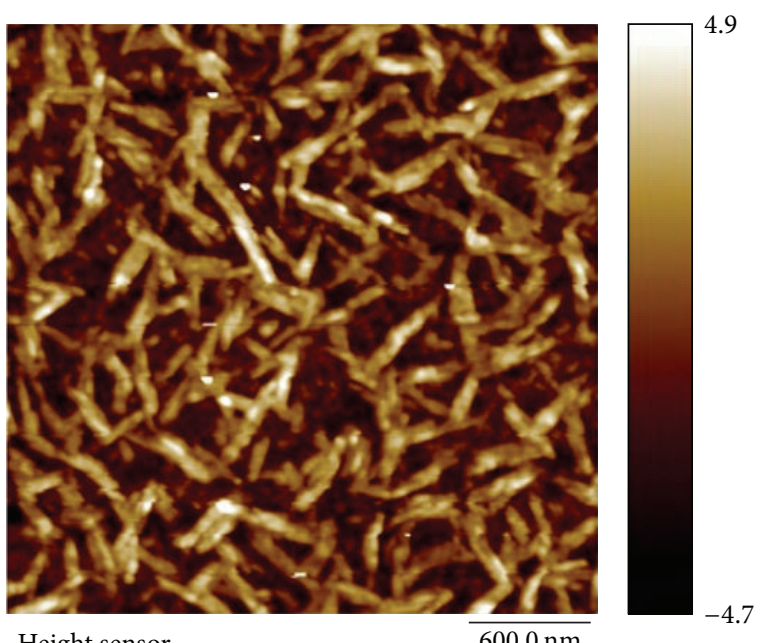

Height sensor

(a)

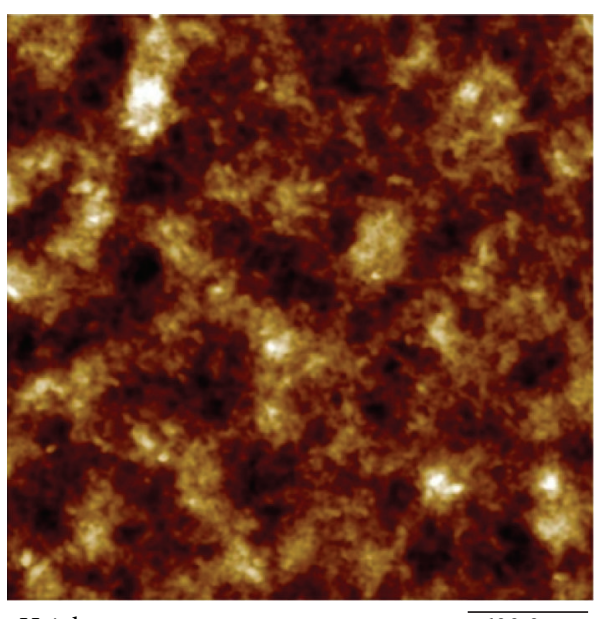

Height sensor

$600.0 \mathrm{~nm}$

(b)

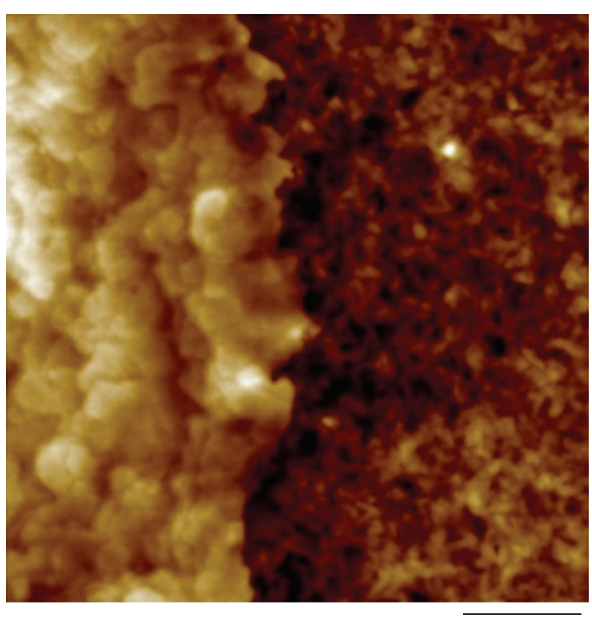

Height sensor

$\overline{600.0 \mathrm{~nm}}$

(c)

FIGURE 5: AFM images of the as-cast (a), best performing-SVT with THF for $4 \mathrm{~s}$ (b), and degraded-SVT with THF for $80 \mathrm{~s}$ (c).
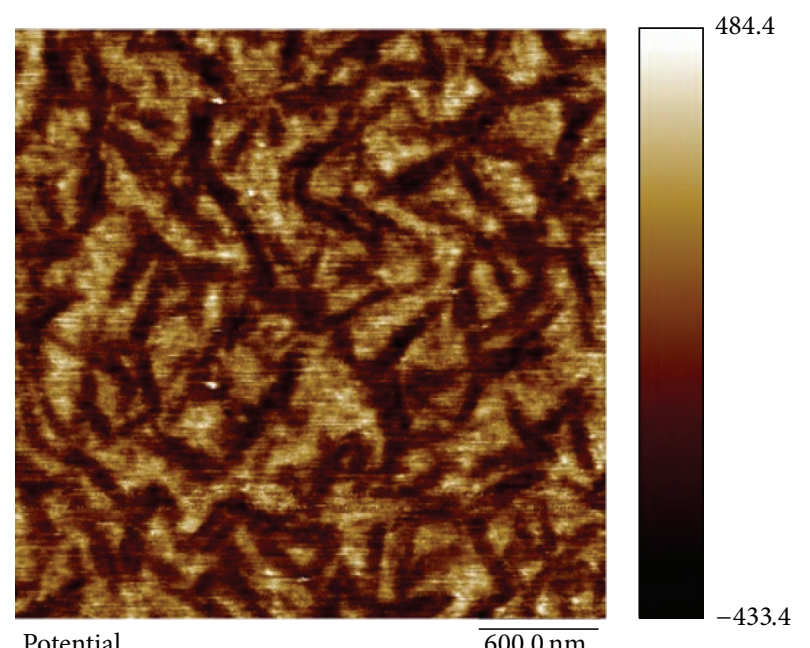

茎

(a)
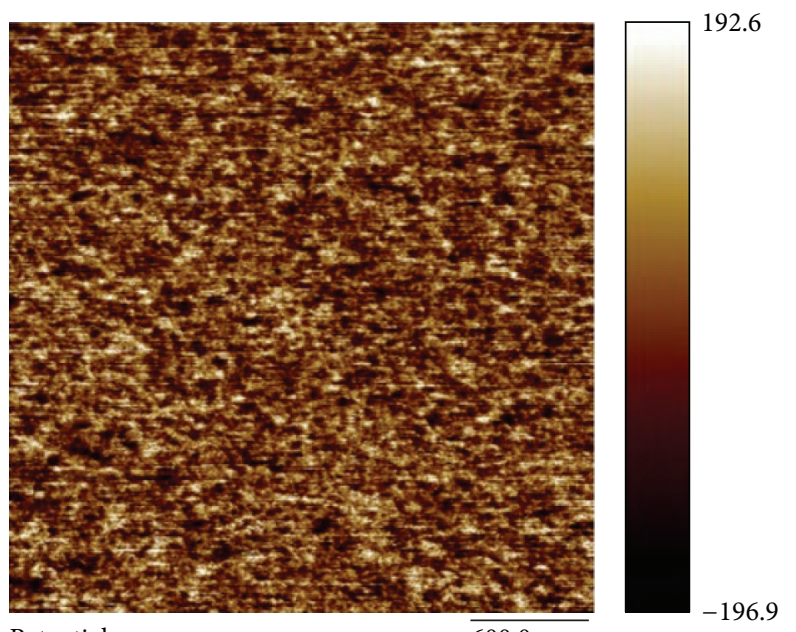

胥

(b)
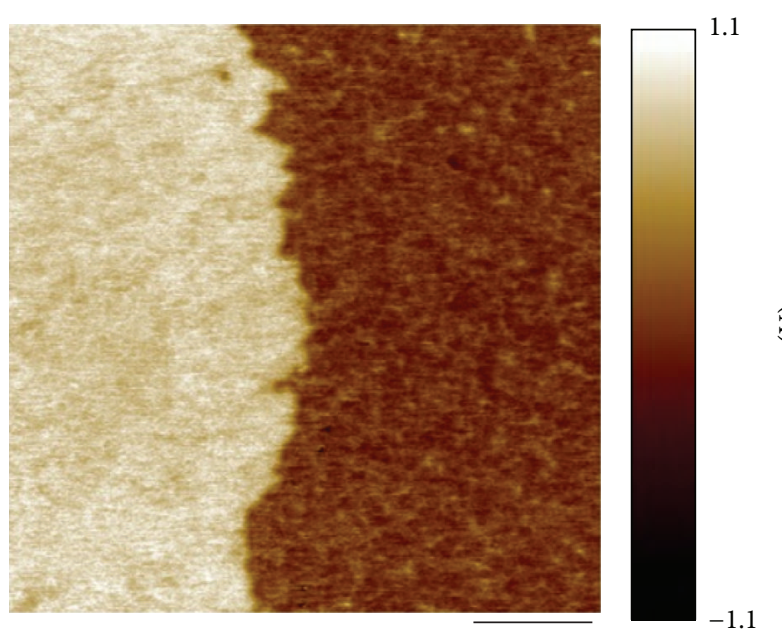

Potential

$600.0 \mathrm{~nm}$

(c)

FIgURE 6: AFM Kelvin probe images of the as-cast (a), best performing-SVT with THF for $4 \mathrm{~s}$ (b), and degraded-SVT with THF for $80 \mathrm{~s}$ (c). 


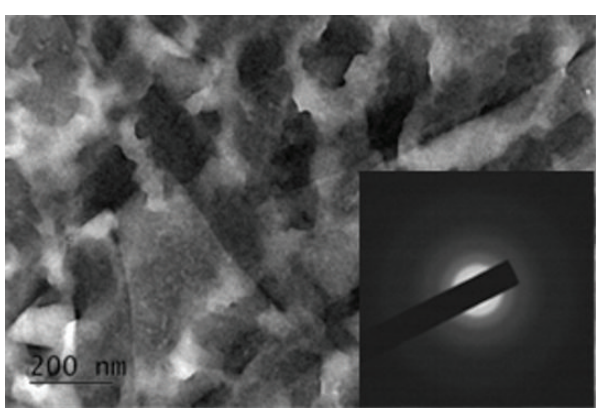

(a)

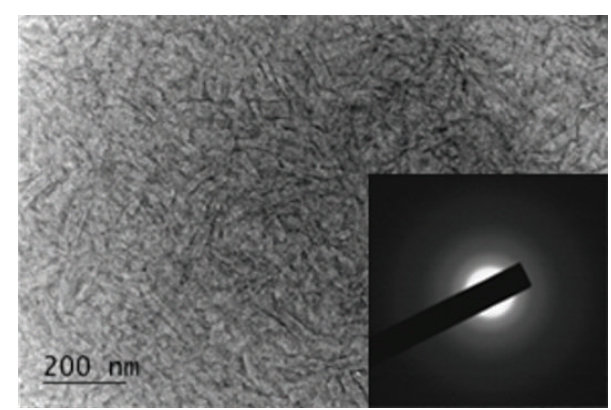

(b)

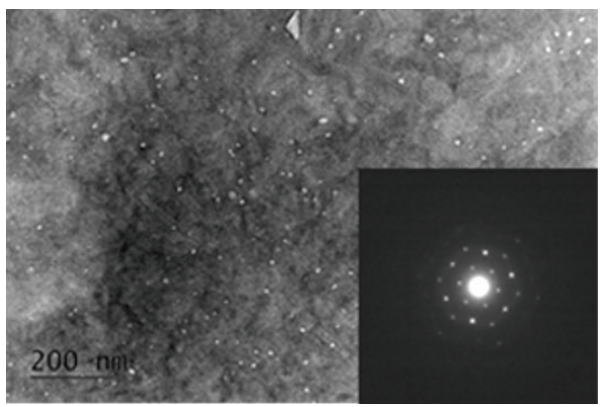

(c)

FIGURE 7: TEM images and corresponding SAED patterns as insets of the as-cast (a), best performing-SVT with THF for $4 \mathrm{~s}$ (b), and degradedSVT with THF for $80 \mathrm{~s} \mathrm{(c).}$

demonstrated that this film was completely amorphous and no crystalline phases existed in its volume.

After the annealing of the film with THF for $4 \mathrm{~s}$, it still remained amorphous (Figure 7(b)), but the morphology changed significantly. In this case the shorter size of the grains was between 20 and $40 \mathrm{~nm}$, which was 10 times lower than for the same direction in as-cast film. The long grain size diminished also in comparison to the initial film. This influence of the annealing on the microstructure of the film could be due to the phase segregation of two components, DPP and PCBM in the depth of the film, which is proved by other authors and by $C-V$ measurements, presented in Figure 4(a).

The morphology of the film annealed for $80 \mathrm{~s}$ presented in Figure 7(c) was more close to this one typical for the $4 \mathrm{~s}$ annealed films. The longer exposal to the THF vapors caused a degradation of the film microstructure resulting in appearance of holes, the white dots on the TEM image in Figure 7(c). A drastic change in the phase composition of this film was detected from the SAED patterns, which evidenced for a single crystalline phase appearance. As the diffraction signal was collected with the diffraction aperture from the central area of the image where a darker, more contrast in electrons matter was registered, we could conclude that this is the image of the more dense crystalline phase giving the single crystalline diffraction patterns. The size of this feature was about $600-800 \mathrm{~nm}$ in diameter, similar to the size of a large particle presented by AFM for the same film on Figure 5(c). The degradation of the device annealed at HTF vapors for $80 \mathrm{~s}$ is probably due to the physical degradation of the active layer together with the formation of a crystalline phase with different charge transfer in its volume.

\section{Conclusion}

In the present work it has been shown how the solvent annealing improves performance of small molecular solar cells in terms of $\mathrm{DPP}(\mathrm{TBFu})_{2}: \mathrm{PC}_{60} \mathrm{BM}$ bulk heterojunction solar cells. Similarly to the thermal annealing solvent treatment of an active layer leads to the structure modification resulting in formation of appropriate conditions for the solar energy conversion such as high crystallinity and morphology. However, solvent annealing was found to be more efficient treatment than the thermal annealing in terms of PCE. Using the capacitance-voltage measurements we have shown that solvent annealing results in more pronounced vertical phase segregation with an emersion of fullerene to the top contact which in turn reduces the photoshunt. Longstanding SVT treatment of the samples resulted in the formation of large acceptor crystallites and bared the donor at the cathode, which in turn negatively affected solar cells' PCE.

\section{Conflict of Interests}

The authors declare that there is no conflict of interests regarding the publication of this paper.

\section{Acknowledgments}

This work was supported by Grant agency of the Czech Republic via project no. 15-05095S, and research 
infrastructures was supported by Projects MŠMT nos. LO1211 and LO1409.

\section{References}

[1] S. Günes, H. Neugebauer, and N. S. Sariciftci, "Conjugated polymer-based organic solar cells," Chemical Reviews, vol. 107, no. 4, pp. 1324-1338, 2007.

[2] S. E. Shaheen, C. J. Brabec, N. S. Sariciftci, F. Padinger, T. Fromherz, and J. C. Hummelen, "2.5\% efficient organic plastic solar cells," Applied Physics Letters, vol. 78, no. 6, pp. 841-843, 2001.

[3] H. Hoppe and N. S. Sariciftci, "Organic solar cells: an overview," Journal of Materials Research, vol. 19, no. 7, pp. 1924-1945, 2004.

[4] H. Hoppe and N. S. Sariciftci, "Morphology of polymer/fullerene bulk heterojunction solar cells," Journal of Materials Chemistry, vol. 16, no. 1, pp. 45-61, 2006.

[5] A. Guerrero, S. Loser, G. Garcia-Belmonte et al., "Solutionprocessed small molecule:fullerene bulk-heterojunction solar cells: impedance spectroscopy deduced bulk and interfacial limits to fill-factors," Physical Chemistry Chemical Physics, vol. 15, no. 39, pp. 16456-16462, 2013.

[6] P. P. Boix, A. Guerrero, L. F. Marchesi, G. Garcia-Belmonte, and J. Bisquert, "Current-voltage characteristics of bulk heterojunction organic solar cells: connection between light and dark curves," Advanced Energy Materials, vol. 1, no. 6, pp. 1073-1078, 2011.

[7] Y. Liu, C.-C. Chen, Z. Hong et al., "Solution-processed smallmolecule solar cells: breaking the $10 \%$ power conversion efficiency," Scientific Reports, vol. 3, article 3356, 2013.

[8] Q. Zhang, B. Kan, F. Liu et al., "Small-molecule solar cells with efficiency over 9\%," Nature Photonics, vol. 9, pp. 35-41, 2015.

[9] S. Jung, A. Sou, K. Banger et al., "All-inkjet-printed, all-airprocessed solar cells," Advanced Energy Materials, vol. 4, no. 14, Article ID 1400432, 2014.

[10] T. M. Eggenhuisen, Y. Galagan, A. F. Biezemans et al., "High efficiency, fully inkjet printed organic solar cells with freedom of design," Journal of Materials Chemistry A, vol. 3, no. 14, pp. 7255-7262, 2015.

[11] M. Kaltenbrunner, M. S. White, E. D. Głowacki et al., "Ultrathin and lightweight organic solar cells with high flexibility," Nature Communications, vol. 3, article 770, 2012.

[12] Z. Huang, E. C. Fregoso, S. Dimitrov et al., "Optimisation of diketopyrrolopyrrole:fullerene solar cell performance through control of polymer molecular weight and thermal annealing," Journal of Materials Chemistry A, vol. 2, no. 45, pp. 19282-19289, 2014.

[13] H. Bronstein, E. Collado-Fregoso, A. Hadipour et al., "Thieno[3,2-b] thiophene-diketopyrrolopyrrole containing polymers for inverted solar cells devices with high short circuit currents," Advanced Functional Materials, vol. 23, no. 45, pp. 5647-5654, 2013.

[14] W. Li, W. S. C. Roelofs, M. M. Wienk, and R. A. J. Janssen, "Enhancing the photocurrent in diketopyrrolopyrrole-based polymer solar cells via energy level control," Journal of the American Chemical Society, vol. 134, no. 33, pp. 13787-13795, 2012.

[15] I. Meager, R. S. Ashraf, S. Mollinger et al., "Photocurrent enhancement from diketopyrrolopyrrole polymer solar cells through alkyl-chain branching point manipulation," Journal of the American Chemical Society, vol. 135, no. 31, pp. 11537-11540, 2013.
[16] S. Loser, C. J. Bruns, H. Miyauchi et al., "Photocurrent enhancement from diketopyrrolopyrrole polymer solar cells through alkyl-chain branching point manipulation," Journal of the American Chemical Society, vol. 133, no. 21, pp. 8142-8145, 2011.

[17] B. Walker, J. Liu, C. Kim et al., "Optimization of energy levels by molecular design: evaluation of bis-diketopyrrolopyrrole molecular donor materials for bulk heterojunction solar cells," Energy \& Environmental Science, vol. 6, no. 3, pp. 952-962, 2013.

[18] W. Li, M. Kelchtermans, M. M. Wienk, and R. A. J. Janssen, "Effect of structure on the solubility and photovoltaic properties of bis-diketopyrrolopyrrole molecules," Journal of Materials Chemistry A, vol. 1, no. 47, pp. 15150-15157, 2013.

[19] M. Vala, J. Krajčovič, S. Luňák Jr., I. Ouzzane, J.-P. Bouillon, and M. Weiter, "HOMO and LUMO energy levels of $\mathrm{N}, \mathrm{N}^{\prime}$ dinitrophenyl-substituted polar diketopyrrolopyrroles (DPPs)," Dyes and Pigments, vol. 106, pp. 136-142, 2014.

[20] J. David, M. Weiter, M. Vala, J. Vyňuchal, and J. Kučerík, “Stability and structural aspects of diketopyrrolopyrrole pigment and its N-alkyl derivatives," Dyes and Pigments, vol. 89, no. 2, pp. 137-143, 2011.

[21] S. Luňák Jr., M. Vala, J. Vyňuchal et al., "Absorption and fluorescence of soluble polar diketo-pyrrolo-pyrroles," Dyes and Pigments, vol. 91, no. 3, pp. 269-278, 2011.

[22] M. Vala, J. Vyňuchal, P. Toman, M. Weiter, and S. Luňák Jr., "Novel, soluble diphenyl-diketo-pyrrolopyrroles: experimental and theoretical study," Dyes and Pigments, vol. 84, no. 2, pp. 176$182,2010$.

[23] S. Luňák Jr., J. Vyňuchal, M. Vala, L. Havel, and R. Hrdina, “The synthesis, absorption and fluorescence of polar diketo-pyrrolopyrroles," Dyes and Pigments, vol. 82, no. 2, pp. 102-108, 2009.

[24] B. Walker, A. B. Tamayo, X.-D. Dang et al., "Nanoscale phase separation and high photovoltaic efficiency in solutionprocessed, small-molecule bulk heterojunction solar cells," Advanced Functional Materials, vol. 19, no. 19, pp. 3063-3069, 2009.

[25] J. Liu, B. Walker, A. Tamayo, Y. Zhang, and T.-Q. Nguyen, "Effects of heteroatom substitutions on the crystal structure, film formation, and optoelectronic properties of diketopyrrolopyrrole-based materials," Advanced Functional Materials, vol. 23, no. 1, pp. 47-56, 2013.

[26] Y. Zhang, X.-D. Dang, C. Kim, and T.-Q. Nguyen, "Effect of charge recombination on the fill factor of small molecule bulk heterojunction solar cells," Advanced Energy Materials, vol. 1, no. 4, pp. 610-617, 2011.

[27] K. Sun, Z. Xiao, E. Hanssen et al., “The role of solvent vapor annealing in highly efficient air-processed small molecule solar cells," Journal of Materials Chemistry A, vol. 2, no. 24, pp. 90489054, 2014.

[28] H. Bürckstümmer, E. V. Tulyakova, M. Deppisch et al., "Efficient solution-processed bulk heterojunction solar cells by antiparallel supramolecular arrangement of dipolar donor-acceptor dyes," Angewandte Chemie International Edition, vol. 50, no. 49, pp. 11628-11632, 2011.

[29] Š. Frebort, M. Vala, S. Luňák Jr. et al., "Diphenylamine endcapped diketopyrrolopyrroles with phenylene-vinylene conjugation extension," Tetrahedron Letters, vol. 55, no. 17, pp. 28292834, 2014.

[30] E. Ripaud, D. Demeter, T. Rousseau et al., "Structure-properties relationships in conjugated molecules based on diketopyrrolopyrrole for organic photovoltaics," Dyes and Pigments, vol. 95, no. 1, pp. 126-133, 2012. 
[31] D. Fernández, A. Viterisi, J. W. Ryan et al., "Small molecule BHJ solar cells based on DPP(TBFu)2 and diphenylmethanofullerenes (DPM): linking morphology, transport, recombination and crystallinity," Nanoscale, vol. 6, no. 11, pp. 5871-5878, 2014.

[32] W. Cambarau, A. Viterisi, J. W. Ryan, and E. Palomares, "Small molecule-based tandem solar cells with solution-processed and vacuum-processed photoactive layers," Chemical Communications, vol. 50, no. 40, pp. 5349-5351, 2014.

[33] A. T. Mallajosyula, S. Sundar Kumar Iyer, and B. Mazhari, "Capacitance-voltage characteristics of P3HT:PCBM bulk heterojunction solar cells with ohmic contacts and the impact of single walled carbon nanotubes on them," Organic Electronics, vol. 13, no. 7, pp. 1158-1165, 2012.

[34] F. Fabregat-Santiago, G. Garcia-Belmonte, I. Mora-Seró, and J. Bisquert, "Characterization of nanostructured hybrid and organic solar cells by impedance spectroscopy," Physical Chemistry Chemical Physics, vol. 13, no. 20, pp. 9083-9118, 2011.

[35] G. Garcia-Belmonte and J. Bisquert, "Open-circuit voltage limit caused by recombination through tail states in bulk heterojunction polymer-fullerene solar cells," Applied Physics Letters, vol. 96, no. 11, Article ID 113301, 2010.

[36] T. S. Ripolles-Sanchis, S. R. Raga, A. Guerrero et al., "Molecular electronic coupling controls charge recombination kinetics in organic solar cells of low bandgap diketopyrrolopyrrole, carbazole, and thiophene polymers," The Journal of Physical Chemistry C, vol. 117, no. 17, pp. 8719-8726, 2013.

[37] A. Guerrero, B. Dörling, T. Ripolles-Sanchis et al., "Interplay between fullerene surface coverage and contact selectivity of cathode interfaces in organic solar cells," ACS Nano, vol. 7, no. 5, pp. 4637-4646, 2013.

[38] G. Garcia-Belmonte, A. Guerrero, and J. Bisquert, "Elucidating operating modes of bulk-heterojunction solar cells from impedance spectroscopy analysis," Journal of Physical Chemistry Letters, vol. 4, no. 6, pp. 877-886, 2013.

[39] A. Kovalenko, A. Guerrero, and G. Garcia-Belmonte, "Role of vertical segregation in semitransparent organic photovoltaics," ACS Applied Materials and Interfaces, vol. 7, no. 2, pp. 1234-1239, 2015.

[40] I. Etxebarria, A. Guerrero, J. Albero, G. Garcia-Belmonte, E. Palomares, and R. Pacios, "Inverted vs standard PTB7:PC70BM organic photovoltaic devices. the benefit of highly selective and extracting contacts in device performance," Organic Electronics: Physics, Materials, Applications, vol. 15, no. 11, pp. 2756-2762, 2014.

[41] T. Wang, N. W. Scarratt, H. Yi et al., "Vertical stratification and its impact on device performance in a polycarbazole based copolymer solar cells," Journal of Materials Chemistry C, vol. 3, no. 16, pp. 4007-4015, 2015.

[42] H. Hoppe, T. Glatzel, M. Niggemann, A. Hinsch, M. C. LuxSteiner, and N. S. Sariciftci, "Kelvin probe force microscopy study on conjugated polymer/fullerene bulk heterojunction organic solar cells," Nano Letters, vol. 5, no. 2, pp. 269-274, 2005.

[43] R. Berger, A. L. Domanski, and S. A. L. Weber, "Electrical characterization of organic solar cell materials based on scanning force microscopy," European Polymer Journal, vol. 49, no. 8, pp. 1907-1915, 2013.

[44] M. Scherer, R. Saive, D. Daume, M. Kröger, and W. Kowalsky, "Sample preparation for scanning Kelvin probe microscopy studies on cross sections of organic solar cells," AIP Advances, vol. 3, no. 9, Article ID 092134, 2013.
[45] S. Kitamura and M. Iwatsuki, "High-resolution imaging of contact potential difference with ultrahigh vacuum noncontact atomic force microscope," Applied Physics Letters, vol. 72, no. 24, pp. 3154-3156, 1998.

[46] A. Kikukawa, S. Hosaka, and R. Imura, "Silicon pn junction imaging and characterizations using sensitivity enhanced Kelvin probe force microscopy," Applied Physics Letters, vol. 66, pp. 3510-3512, 1995. 

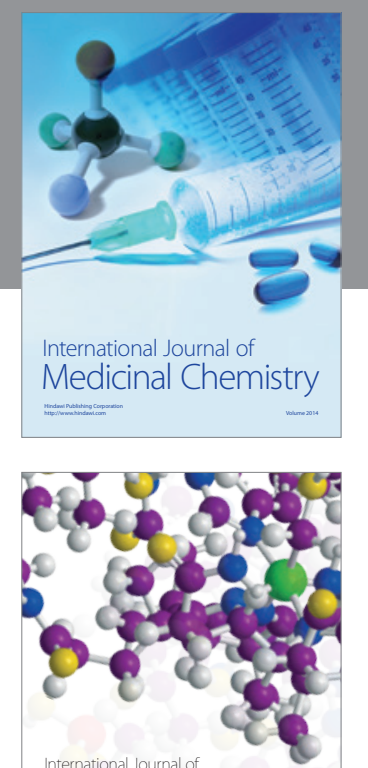

\section{Carbohydrate} Chemistry

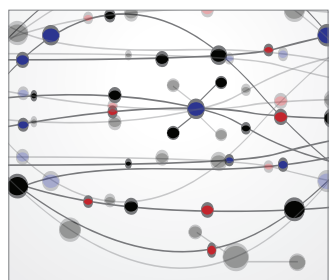

The Scientific World Journal
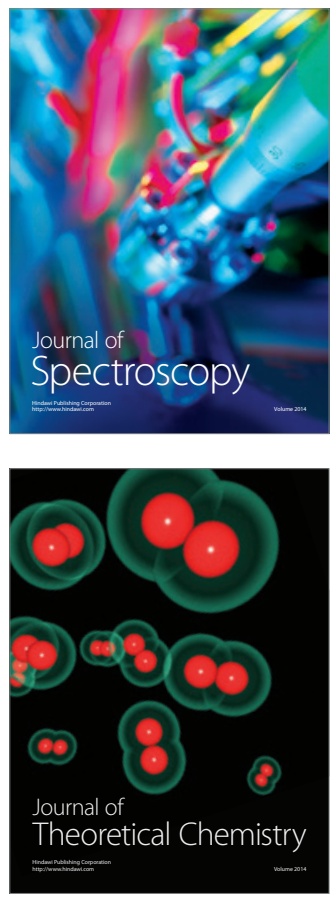
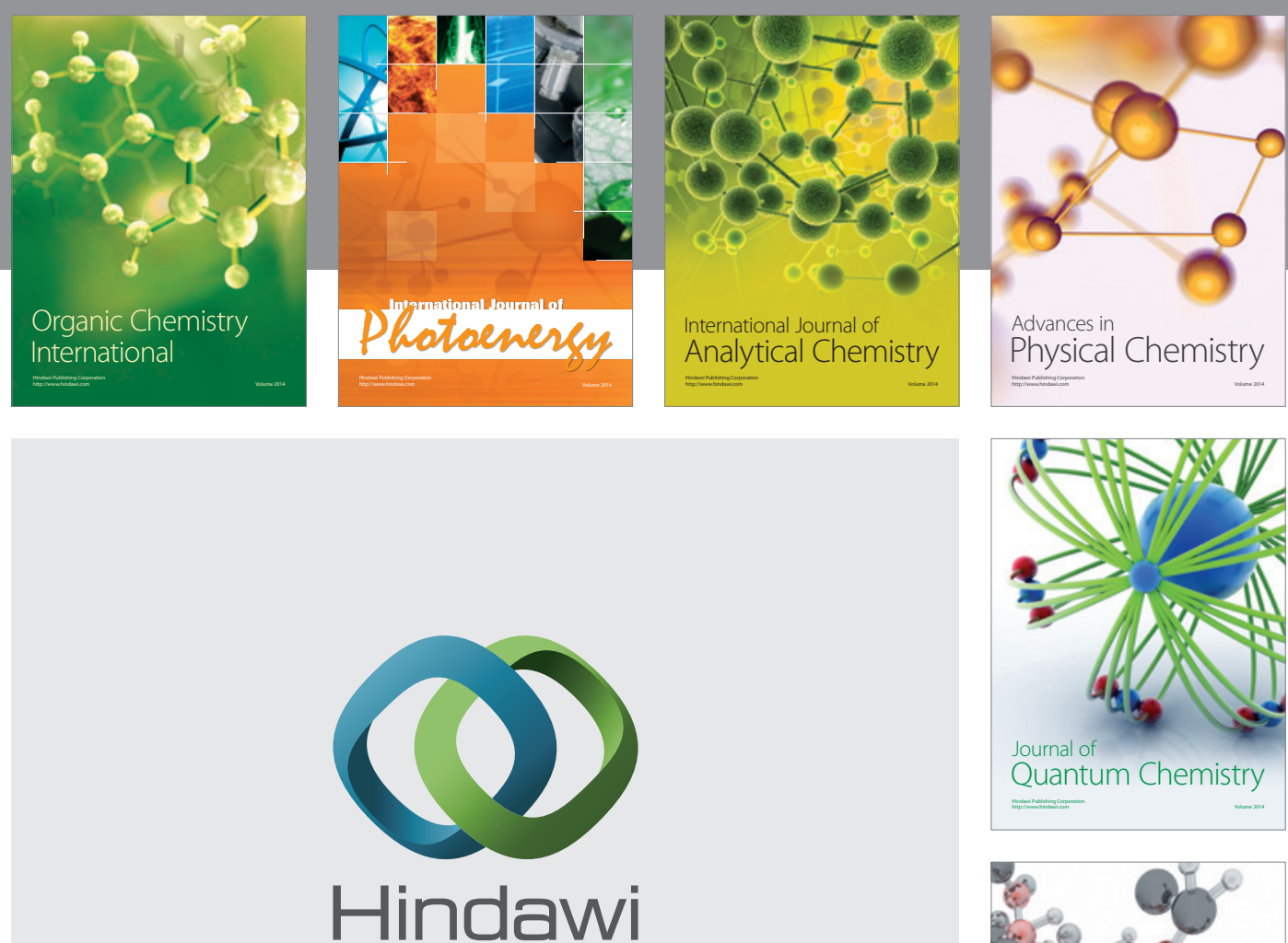

Submit your manuscripts at

http://www.hindawi.com

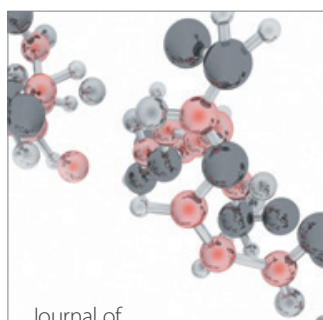

Analytical Methods

in Chemistry

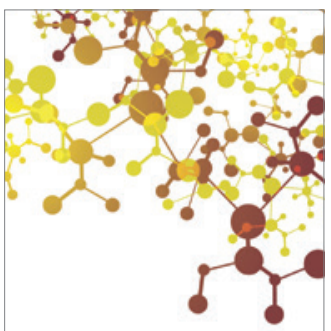

Journal of

Applied Chemistry

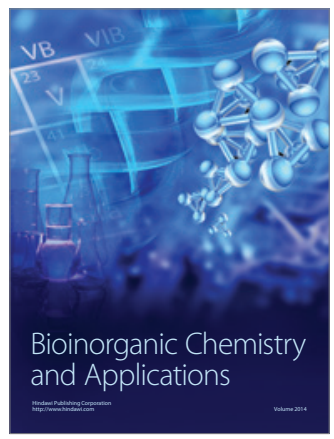

Inorganic Chemistry
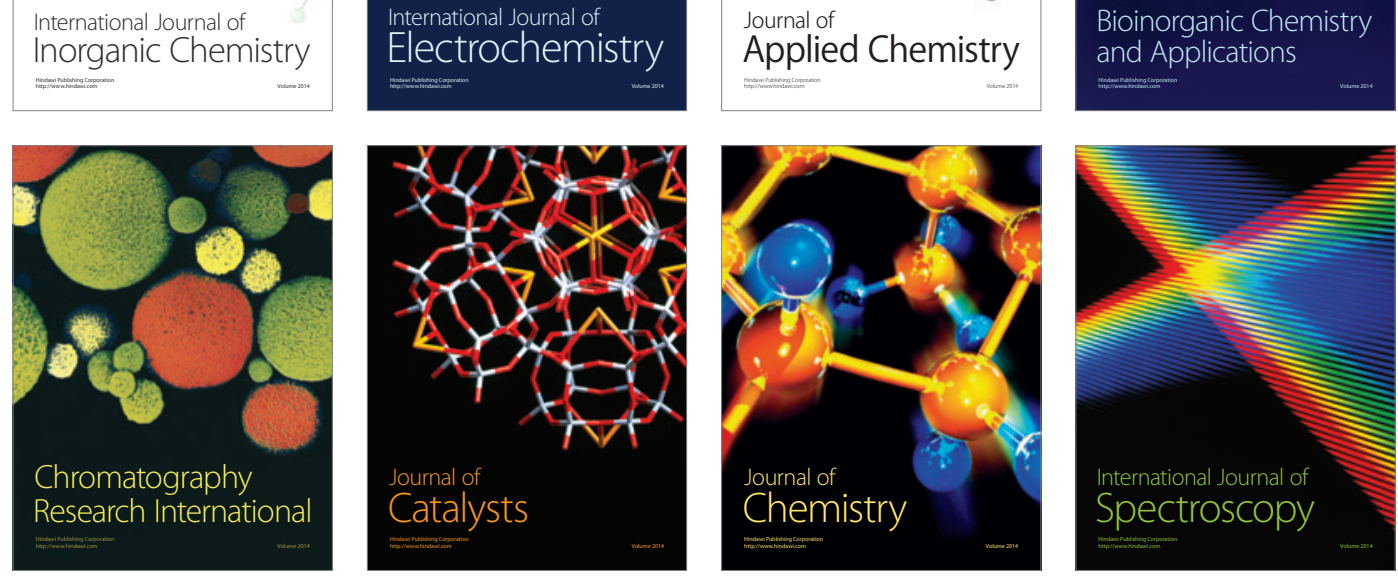